\title{
EVALUATION OF ANTI-CANCER EFFECT OF DIFFERENT CONCENTRATIONS OF BLACK RASPBERRIES EXTRACT ON ORAL SQUAMOUS CELL CARCINOMA CELL LINE (IN VITRO STUDY)
}

\author{
Hatem Mahmoud Ali", Dina Soliman Khater ${ }^{* *}$ and Sara Mohammed Abd El-Wahed***
}

\begin{abstract}
Background: Black Raspberry has a wide range of pharmacological and therapeutic aspects including anti-inflammatory and antioxidant activities. Moreover, the effect of Black Raspberry has been studied in many cancers such as human cervical, esophageal and colorectal cancer and showed cytotoxic and anti-proliferative effects against these types of cancer.
\end{abstract}

Aim: To identify the possible anti-cancer effect of Black Raspberry on Oral Squamous Cell Carcinoma cell line.

Material and methods: Human tongue squamous cell carcinoma cell line was divided into 3 groups: one control group, second group treated with Black Raspberry, and the third group treated with Doxorubicin, each of the two treatments was applied for 24, 48, 72 hours, respectively. Then, cellular viability was measured using Microculture Tetrazolium assay, cell cycle analysis was done using Flow Cytometry and eventually, apoptotic activity was evaluated using Enzyme-linked Immunosorbent assay.

Results: Black Raspberry succeeded to decrease the percentage of viable and proliferating cells with increasing time. On the other hand, it increased the percentage of apoptotic cells and levels of caspase- 3 .

Conclusion: Black Raspberry has a potential cytotoxic effect on oral squamous cell carcinoma cell line in a dose and time dependent manner, and exerts this action through induction of apoptosis, and its action is comparable to Doxorubicin action.

* B.D.S (Cairo University) and Demonstrator of Oral and Maxillofacial Pathology, Faculty of Dentistry, The British University in Egypt.

** Professor of Oral and Maxillofacial Pathology, Faculty of Dentistry, Cairo University.

*** Lecturer of Oral and Maxillofacial Pathology, Faculty of Dentistry, The British University in Egypt. 


\section{INTRODUCTION}

Oral Squamous Cell Carcinoma (OSCC) is the commonest malignancy in head and neck area which accounts for $95 \%$ of oral malignant lesions in the developing countries.

In spite of advances in treatment modalities in targeted therapy, the prognosis of OSCC is poor due to invasion, metastasis and recurrence. Besides the limitations of current cancer management, available cytotoxic drugs are not easily affordable or available in certain places and their use is also associated with a number of undesirable side and adverse effects. As a consequence, a large proportion of the population prefers to patronize complementary and alternative medicine which has a number of advantages compared to standard drugs ${ }^{(\mathbf{1}, 2)}$.

Epidemiological studies have demonstrated a correlation between high intake of vegetables and fruit and a decreased incidence of cancer in multiple organ sites in humans. Moreover, It has been reported that regular consumption of fruit and vegetables improve overall human health and wellbeing by preventing many diseases including several types of cancer. It is thought that the chemopreventive effects of vegetables and fruit are due to their contents of phytochemicals, vitamins, vitamin precursors and minerals ${ }^{(3,4)}$.

Berry fruits are widely consumed in our diet and have attracted much attention due to their potential human health benefits. Black Raspberry (BR) has been extensively evaluated for its impact on human health due to its rich phytochemical content. Studies have showed that BR fruits are useful for therapy of various types of cancers such as esophagus, cervical and colon cancers by inhibiting tumor progression via its anti-proliferative, anti-inflammatory and antioxidant activities. From here, this work was directed to evaluate the anticancer effect of BR on OSCC using state of the art techniques as MTT essay, flow cytometry and ELISA assay ${ }^{(5,6,7)}$.

\section{MATERIAL}

Cell line of human tongue squamous cell carcinoma (SCC15) was purchased from Innovation Lab, VACSERA, Cairo, Egypt. Black raspberry extract powder was purchased from Berrihealth Company (Address: 7511 East Gate Road, Henderson, NU89011 U.S.A). Doxorubicin (Dox) was purchased from Sigma Aldrich (Munich, Germany).

\section{METHODS}

Cell line of human tongue squamous cell carcinoma (SCC15) was sub-cultured, and then divided into 3 groups, first group was treated with $\mathrm{BR}$, second group treated with Dox, which was used as a reference drug, in addition to a control group not exposed to BR or Dox. In each group, the percentage of viability of OSCC cells was measured by MTT assay, cell cycle and apoptosis analysis were assessed using flow cytometry at 3 time intervals (24, 48 and 72 hours), respectively. Furthermore, apoptosis indicator Caspase 3 was also measured by means of ELISA at the same intervals.

\section{RESULTS}

\section{1-Cell viability:}

The cell viability percent showed a gradual decrease with increasing doses of the proposed treatments (BR and Dox).

\section{2-Cell cycle analysis:}

(a) In G0-G1 phase, a gradual decrease in the amount of cells entering the cell cycle was observed among the groups with increasing time. Regarding the $\mathbf{S}$ phase, the BR treated groups at $24 \mathrm{~h}, 48 \mathrm{~h}$ and $72 \mathrm{~h}$, respectively, showed a gradual decrease in the amount of cells from one group to the other with increasing time. Similarly, this was observed when comparing the Dox treated groups. Unlike the G0G1 and S phases, a gradual increase in the amount of cells in G2-M phase with increasing time was 
detected in BR and Dox treated groups at different time intervals (24h, $48 \mathrm{~h}$ and $72 \mathrm{~h})$.

\section{Statistical analysis}

Statistical analysis revealed high statistical significance among the BR treated groups at $24 \mathrm{~h}$, $48 \mathrm{~h}$ and $72 \mathrm{~h}$ time intervals in G0-G1, S phase and G2-M phase.

\section{(b) Apoptotic phase}

A gradual increase in the amount of apoptotic cells in the BR and Dox treated groups was revealed among the three intervals.

\section{Statistical analysis}

The gradual increase in the amount of apoptotic cells showed a high statistical significant difference among the BR and Dox treated groups (figure 1).

\section{(c) Analysis of DNA histogram and Dot Plots:}

The percentage of apoptotic cells showed an increase with BR and Dox treatment to OSCC cell line. The highest value was observed in BR at 72h time interval (19.27\%). However, they were almost undetectable in the control group. Apoptotic cells were almost equally distributed between early and late apoptotic phases in all the treated groups (figure 2).

\section{3- Detection of Caspase-3 enzyme}

Levels of caspase- 3 were elevated in all treated study groups of BR and Dox at different time intervals $24 \mathrm{~h}, 48 \mathrm{~h}$ and $72 \mathrm{~h}$. Highest concentration was observed in Dox (72h) group.

\section{Statistical analysis}

A highly significant difference was observed among BR treated groups with increase time of treatment from $24 \mathrm{~h}$ to $48 \mathrm{~h}$ and $72 \mathrm{~h}$. The same was observed among the 3 Dox treated groups (figure 3).

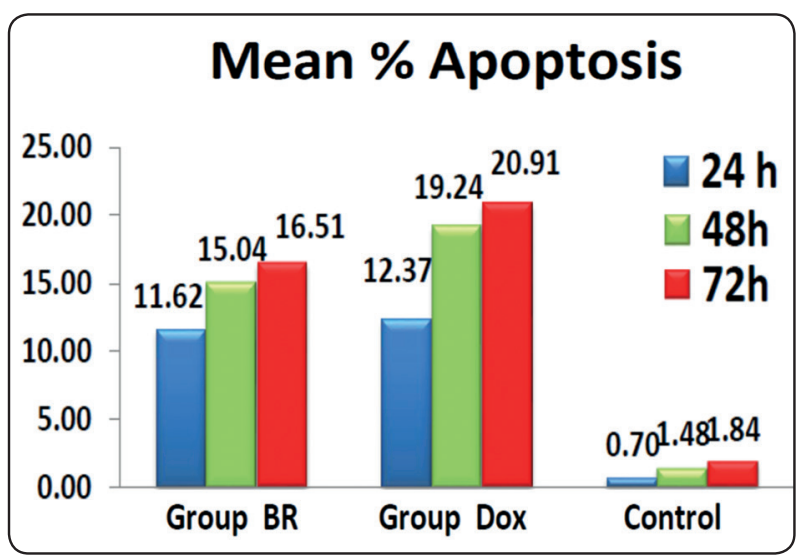

Fig. (1): A bar chart showing mean percentage of total apoptosis in BR and Dox groups in comparison to the control group at $24 \mathrm{~h}, 48 \mathrm{~h}$ and $72 \mathrm{~h}$ time intervals.

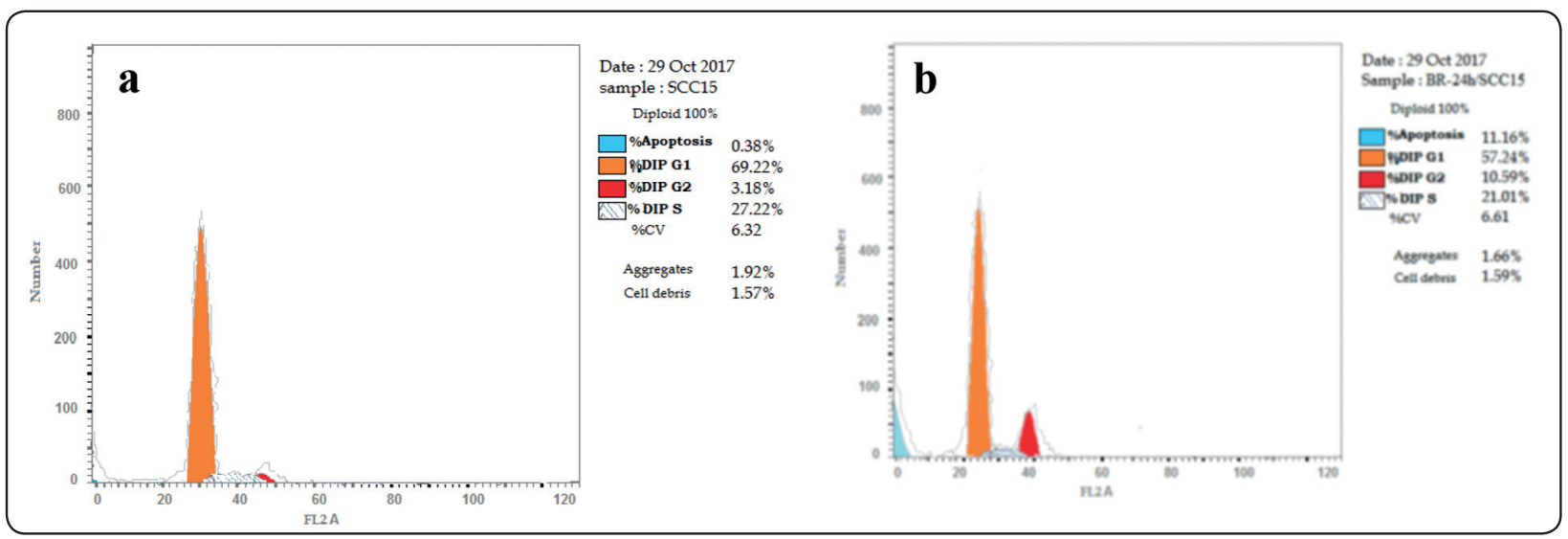




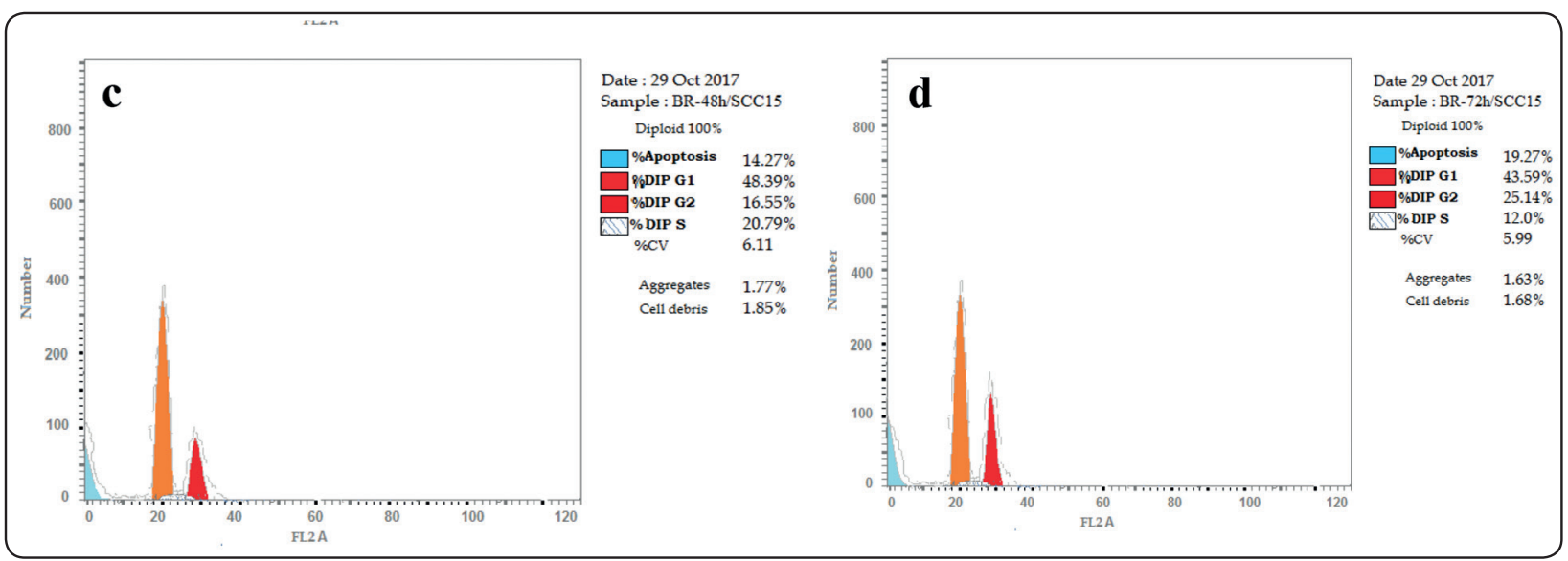

Fig. (2): DNA histograms of (a) control group showing fractions of apoptotic rate of $0.38 \%$ (blue peak) and highest peak of cells (orange peak) in the G1 phase preparing to enter the cell cycle, (b) BR (24h) group showing increase in the apoptotic rate (blue) to $11.16 \%$ with the highest peak $(57.24 \%$ ) in the G1 phase (orange peak), (c) BR (48h) group showing more increase in the apoptotic rate to $14.27 \%$ and the highest peak of cells $(48.39 \%)$ in the G1 phase (orange) and (d) BR (72h) group showing further increase in the apoptotic rate to $19.27 \%$ (blue) and the highest peak of cells (43.59\%) in the G1 phase(orange).

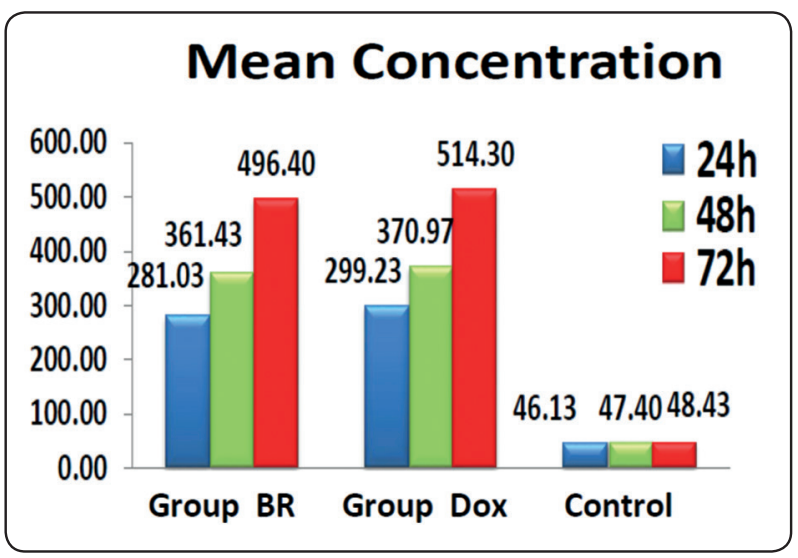

Fig (3): A bar chart showing mean concentrations of caspase-3 in the treated groups in comparison to the control group at $24 \mathrm{~h}, 48 \mathrm{~h}$ and $72 \mathrm{~h}$ time intervals.

\section{DISCUSSION}

OSCC is a devastating disease that constitutes a significant proportion, comprising $95 \%$ of head and neck cancers. The overall survival rate in most countries ranges between $45 \%$ and $50 \%$ and has not shown any significant improvement during the past few decades. Tongue cancer was the cell line of choice in the present study as it was reported to be the most common type of OSCC and, by far, the most encountered in our daily practice. Moreover, its surgical treatment modality disabled patients greatly ${ }^{(8)}$.

Over the last decade numerous lines of evidence have supported clinical investigations utilizing BR as inhibitor of cancer or premalignancy in high risk human cohorts. First, mounting epidemiological evidence shows increased consumption of plant based diets is associated with decreased cancer risk. Second, strong preclinical results in animal models report that BR inhibit cancers of the oral cavity, esophagus, colon, breast and skin through targeting processes of proliferation, inflammation, angiogenesis and apoptosis. Third, from a composition stand point $\mathrm{BR}$ is rich in vitamins, minerals, fiber, anthocyanins, total phenolics and other bioactive components with cancer inhibitory capacity ${ }^{(9,10)}$.

Multiple techniques were used, including MTT assay, Flow Cytometry and ELISA. In order to judge the beneficial action of BR on OSCC, it was very important to use a reference chemotherapeutic drug for comparing its results with those of BR groups. Dox was chosen as being regarded as one of the most powerful anti-neoplastic agents. Concerning $\mathrm{BR}$, findings of the present study revealed potential 
cytotoxic effect of BR on OSCC cell line in a dose and time-dependent manner, as it succeeded to decrease the percentage of viable and proliferating cells with increasing its doses. On the other hand, it increased the percentage of apoptotic cells and levels of caspase-3. This could be attributed to its anti-proliferative, antiinflammatory and antioxidant activities.

The anticancer effect of BR, which is revealed in this work, is in agreement with Knobloch et al. (2015) ${ }^{(11)}$ and Warner et al. (2015) ${ }^{(12)}$. In the same context, Zhang et al. (2011) ${ }^{(13)}$, Kresty et al. (2016) ${ }^{(7)}$, and Ibrahim. (2017) ${ }^{(14)}$ reported similar results in cervical cancer, esophageal cancer and colorectal cancer respectively. Moreover, decreasing the $\mathrm{IC}_{50}$ value with increasing time of treatment from $24 \mathrm{~h}$ to $72 \mathrm{~h}$ time intervals indicates that the cytotoxic effect of BR against OSCC cell line could be efficiently exerted with the same efficacy either by a high dose of BR for limited time, or reduced $\mathrm{BR}$ dose for prolonged time.

The remarkable decrease in the percent of cells in the G0-G1 and S phases of cell cycle in the current work indicates that there is change in the DNA content of cells entering the cell cycle, leading to deregulated cell cycle and inhibition of cancer cell growth and proliferation. On the contrary, the results showed an increase in the percentage of cancer cells in $\mathrm{G} 2 / \mathrm{M}$ phase, which indicates that BR has caused irreparable DNA damage, which led to cell cycle arrest and accumulation of cells in this phase of cell cycle in preparation to apoptosis. This was in accordance with Feng et al. (2004) ${ }^{(15)}$.

Furthermore, the levels of caspase-3 were markedly elevated in comparison to the control groups, which indicate an active process of apoptosis. This result was matching with that of Rodrigo et al. (2006) ${ }^{(\mathbf{1 6})}$. This finding augments the belief that BR has exerted its anticancer effect via activation of caspase- 3 through the mitochondrial pathway, which is the main effector caspase and the hallmark of apoptosis.

\section{CONCLUSION}

The present study clearly demonstrated the potential cytotoxic effect of BR on OSCC cell line in a dose and time-dependent manner as well as its promising efficacy against OSCC cells, which was comparable to that of the well-known chemotherapeutic drug Dox with less toxicity and side effects.

\section{REFERENCES}

1. Chidambaram, M., Manavalan, R., \& Kathiresan, K. (2011). Nanotherapeutics to overcome conventional cancer chemotherapy limitations. J. Pharm. Pharm. Sci., 14 (1), 67-77.

2. Rivera, C., \& Venegas, B. (2014). Histological and molecular aspects of oral squamous cell carcinoma (Review). Oncology Letters, 8(1), 7-11.

3. Mukhtar,H.,\&Ahmad,N.(1999).CancerChemoprevention: Future Holds in Multiple Agents. Toxicology And Applied Pharmacology, 158(3), 207-210.

4. Ozgen, M., Wyzgoski, F., Tulio, A., Gazula, A., Miller, A., Scheerens, J., Reese, R., \& Wright, S. (2008). Antioxidant Capacity and Phenolic Antioxidants of Midwestern Black Raspberries Grown for Direct Markets Are Influenced by Production Site. Hortscience, 43(7), 2039-2047.

5. Wang, L., \& Stoner, G. (2008). Anthocyanins and their role in cancer prevention. Cancer Letters, 269(2), 281-290.

6. Cho, H., Jung, H., Lee, H., Yi, H., Kwak, H., \& Hwang, K. (2015). Correction: Chemopreventive activity of ellagitannins and their derivatives from black raspberry seeds on HT-29 colon cancer cells. Food \& Function, 6(8), 2861-2861.

7. Kresty, L., Frankel, W., Hammond, C., Baird, M., Mele, J., Stoner, G., \& Fromkes, J. (2006). Transitioning From Preclinical to Clinical Chemopreventive Assessments of Lyophilized Black Raspberries: Interim Results Show Berries Modulate Markers of Oxidative Stress in Barrett's Esophagus Patients. Nutrition And Cancer, 54(1), 148156 .

8. Jemal A, Siegel R, Ward E, Hao Y, Xu J, et al. Cancer statistics,CA Cancer J Clin. 2008; 58:71-96. Jemal, A., Siegel, R., Ward, E., Hao, Y., Xu, J., Murray, T., \& Thun, M. (2008). Cancer Statistics, 2008. CA: A Cancer Journal For Clinicians, 58(2), 71-96. 
9. Cooke,D.,Steward,W.,Gescher,A.,\& Marczylo, T. (2005). Anthocyans from fruits and vegetables - Does bright colour signal cancer chemopreventive activity?. European Journal Of Cancer, 41(13), 1931-1940.

10. Duncan, F., Martin, J., Wulff, B., Stoner, G., Tober, K., Oberyszyn, T., Kusewitt, D., \& Van Buskirk, A. (2009). Topical Treatment with Black Raspberry Extract Reduces Cutaneous UVB-Induced Carcinogenesis and Inflammation. Cancer Prevention Research, 2(7), 665-672.

11. Knobloch, T., Uhrig, L., Pearl, D., Casto, B., Warner, B., Clinton, S., Sardo-Molmenti, C., Ferguson, J., Daly, B., Riedl, K., Schwartz, S., Vodovotz, Y., Buchta, A., Schuller, D., Ozer, E., Agrawal, A., \& Weghorst, C. (2015). Suppression of Proinflammatory and Prosurvival Biomarkers in Oral Cancer Patients Consuming a Black Raspberry Phytochemical-Rich Troche. Cancer Prevention Research, 9(2), 159-171.

12. Warner, B., Knobloch, T., Casto, B., Holpuch, A., Accurso, B., Summersgill, K., \& Weghorst, C. (2015). Topical Black Raspberries Reduce Proliferation and Survivin/Birc5 in Established OSCC. Oral Surgery, Oral Medicine, Oral Pathology And Oral Radiology, 120(3), e140.
13. Zhang, Z., Knobloch, T., Seamon, L., Stoner, G., Cohn, D., Paskett, E., Fowler, J., \& Weghorst, C. (2011). A black raspberry extract inhibits proliferation and regulates apoptosis in cervical cancer cells. Gynecologic Oncology, 123(2), 401-406.

14. Ibrahim, T. (2017). Anticancer Effect of Black Raspberry and Apricot Juice against Colon Cancer Induced by Azoxymethane in Male Rats. International Journal Of Advanced Research In Biological Sciences (IJARBS), 4(8), 187-196.

15. Feng, Y., Chen, S., Stoner, G., \& Wang, D. (2004). Black raspberry extracts induce growth inhibition and apoptosis in human oral carcinoma cells. American Association for Cancer Research, 64 (7), 166-167.

16. Rodrigo, K., Rawal, Y., Renner, R., Schwartz, S., Tian, Q., Larsen, P., \& Mallery, S. (2006). Suppression of the Tumorigenic Phenotype in Human Oral Squamous Cell Carcinoma Cells by an Ethanol Extract Derived From Freeze-Dried Black Raspberries. Nutrition And Cancer, 54(1), 58-68. 